\title{
CoMENTÁRIO: TópICA del TROPISMO: SObRE LA METÁFORA ALIMENTARIA
}

\author{
Cristóbal Durán Rojas ${ }^{1}$
}

Referência do texto comentado: SALVATERRA, Valeria Campos. Comer al otro: retoricas de la alimentación: Una lectura del seminario inédito Manger l'autre de Jacques Derrida (1989 - 1990). Trans/Form/Açáa: revista de filosofia da Unesp, vol. 43, n. 4, p. 343 - 368, 2020.

Quisiera preguntarme en qué sentido se puede afirmar que comer constituye una metáfora. Ello supondría, posiblemente, que la metáfora ya cuenta con un lugar. ¿Hay un comer que no sea en sentido metafórico? ¿Comer es una metáfora cuando la advertimos como tal, metafóricamente? Como se sabe, en el primer apartado de Ecce Homo, Nietzsche presenta una pequeña doctrina de la alimentación. De la alimentación depende la salvación de la humanidad, nos dice. Y formula así su cuestión central: “¿Cómo has de alimentarte en tu caso para lograr tu máximo de fuerza, de virtú [vigor] al estilo del Renacimiento, de virtud libre de moralina?" (NIETZSCHE, 2016, p. 796). La alimentación, asociada a la fuerza y al vigor, tendría efectos en el espíritu: así, el espíritu alemán sería una indigestión, que procede de "intestinos revueltos" y "no llega a dar término a nada" (NIETZSCHE, 2016, p. 797). O la dieta inglesa, ese "canibalismo", "que le confiere al espíritu pies pesados". El espíritu se indigesta o se enlentece, y ello interpela al modo en que se alimenta el filósofo, la filósofa. Los pensamientos que se acercan con pies de palomas se muestran aquí pesados, revueltos. El cuerpo que escribe "tiene que conocer el tamańo de su estómago” (NIETZSCHE, 2016, p. 797) - pero

1 Profesor asociado de la Facultad de Educación y Ciencias Sociales, Universidad Andrés Bello, Santiago - Chile. (D) https://orcid.org/0000-0001-7442-6627. E-mail: cristobal.duran@unab.cl

http://doi.org/10.1590/0101-3173.2020.v43n4.23.p349

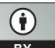

This is an open-access article distributed under the terms of the Creative Commons Attribution License. 
hay que preguntarse en qué sentido es preciso una metáfora para pensar entre el estómago y el conocimiento.

La metáfora es un ejercicio de sustitución, un transporte que transforma el sentido. Hay una tesis sobre la metáfora puesta en juego cuando se habla de todo lo asociado al acto de comer. Tanto Salvaterra (2020) como Nietzsche estarían de acuerdo en que no se puede silenciar a la alimentación. Pero para Salvaterra (2020), como lo muestra en su texto, la alimentación es una trópica, que hace del comer (comer-algo-otro), "una figura clave de desplazamiento o transposición semántica para referir oblicuamente a temas que son, de hecho y de derecho, los más importantes para el discurso filosófico". Referir oblicuamente: esa es la labor de la metáfora. Pero no creamos que se trata de una metáfora "en sentido corriente", como nos recordará Salvaterra (2020) más de una vez: su función no es tan sólo ilustrativa para referirse al concepto. En realidad, la alimentación auxilia a la discursividad filosófica: le permite a esta asimilar e introyectar normatividades discursivas ajenas y, mediante ese gesto, le permite soñar con que ella se desentiende del comer, o lo trata sólo como un "tema".

Tengo la impresión de que Salvaterra (2020) nos recuerda que hay, en vilo, una cuestión del comer. Y que ella está mucho antes de que adoptemos una posición, una tesis respecto a ella. Pareciera entonces no ser un tropo entre otros. ¿O sí lo es? ¿Qué sucedería si fuera el tropo de los tropos? ¿Si fuera la fuente, el lugar desde el cual emana el movimiento generalizado de una trópica? Una retórica de la alimentación preside el argumento, ya que el gesto alimenticio reproduce la metaforicidad, que responde a una "dinámica de incorporación". Una metáfora que, sin embargo, es un "tropo de sustitución metonímica que le es fundamental”, "que deja al descubierto su dinámica estructural de envíos sin origen determinable", y que exige que nos preguntemos por qué la metáfora sería una metáfora de la metonimia, y viceversa. Salvaterra (2020) advierte que ello se debe a que esta metáfora-metonimia hace uso de lo exterior para nombrar lo interior. Esto nos da una idea del poder y la primacía de la metáfora, ya que incluso ella puede pasar por metonimia. ¿Por qué la metáfora?

Salvaterra (2020, p. 352) leerá Derrida para afirmar que “[...] la lógica del discurso filosófico consiste [...] en una lógica de la incorporación a partir de la metaforización" ("introyección” e "incorporación”, dirá, subrayando esta última) y para afirmar que la metaforización podría designar, también, a "la forma general de la introyección de un elemento alógeno en el discurso filosófico" (Salvaterra (2020) subraya a Derrida). ¿Comer es incorporar o introyectar? ¿O 
acaso sería lo mismo? No intentamos hacer aquí una pregunta crítica, para discernir sus fronteras, si es que las hay. La metafórica generalizada de Derrida, y que Salvaterra (2020) suscribe para prolongarla en su propia generalización de la metafórica del comer parece requerir de ambas, parece arrastrar a ambas. Metáfora/metonimia, incorporación/introyección: todas ellas parecen encaminarse a mostrar que la estructura retórica de la filosofía tiene una forma alimenticia, e incluso "la esencia misma de la retórica no podría ser explicada de modo "propio" más que por dicha metáfora". Metáfora y metonimia se confunden para subordinarse a la alegoría, como asimilación de lo otro en el discurso. Gracias a ella la metáfora puede ser designada como "mecanismo de aprehensión de lo ajeno".

Una vez más. ¿Por qué recurrir a la metáfora se podría preguntar? Pese a que la generalización de la metafórica impide distinguir entre la figura y lo figurado, nos volvemos a preguntar por qué el tropo del comer nombra "propiamente" la incorporación (otro tropo), precisamente cuando la alimentación "aparece como la metaforización por excelencia de la metaforicidad estructural del discurso filosófico". Tan sólo hacia el final del artículo nos encontramos con la cuestión hacia la cual Salvaterra (2020) parecía conducirnos. En tanto incorporación de lo otro, "pensar" "es como comer". Pero en "el sentido mismo del pensar debería obtenerse de la esencia de la alimentación adecuadamente pensada, y vice versa. El comer no es una metáfora del pensar (en sentido corriente) sino que pensar y comer deben entregarse mutuamente su sentido". Eso nos dice al concluir su artículo. Pensar adecuadamente el comer nos entregaría el sentido "mismo" del pensar. No tendremos ocasión de detenernos en esto. Sólo dejaremos consignada la pregunta. ¿En qué consistirá esta adecuación y este sentido, precisamente si las significaciones aquí, dadas sus contaminaciones, ya no tienen una delimitación precisa? (Zourabichvili, 2011, p. 67)

¿Por qué nos representamos algo yendo desde una metáfora hacia otra? ¿Por qué el pensar parece requerir una estructura referencial, un juego de remisiones? Derrida ha podido descubrir un momento antimetafórico. Leyendo la distinción entre introyección e incorporación, tal como son trabajados por Abraham y Torok (1987) para comprender los procesos de identificación psíquica, descubre una literalidad asociada a la incorporación. La incorporación pretende cumplir en sentido propio lo que solo tiene un sentido figurado. Es una batalla contra la pérdida, que al no poder ser introyectada, se transforma en una incorporación imaginaria y objetivante de 
lo que se perdió. Por eso, se desencadenaría un proceso de desmetaforización, que consistiría en tomar al pie de la letra lo que se entiende en sentido figurado. La incorporación es un rechazo de introyectar y, pese a ello, adopta la forma de introducir un objeto en el cuerpo. La incorporación literalmente cumple la metáfora de la introyección, al sustituir a esta última. Ciertamente el límite es equívoco entre ambas. Pero la incorporación supone una destrucción activa de la figuración, una revocación del acto de introyectar. Sin embargo, Derrida no puede abandonar el círculo de la metáfora: la incorporación "realiza la metáfora oral que preside la introyección” (DERRIDA, 1976, p. 56), se come para no introyectar y, de este modo, la metáfora "se toma 'literalmente' para rechazar su eficacia introyectiva” (DERRIDA, 1976, p. 56). Una metaforización precede a la desmetaforización, y gobierna sus movimientos.

La metáfora parece insoslayable. Impone su buen sentido o su sentido común. Me pregunto si no hay una literalidad que atormenta las estructuras que se pretenden metafóricas, no una que permita fijar la metáfora, sino mostrar cómo cambian las contaminaciones que sus entrecruzamientos producen. Y que quizá permitan entender que no hay nada de metafórico en la afirmación nietzscheana de un espíritu que es una indigestión. Esa literalidad no tendría relación con tratar de fijar una metáfora como si ella adquiriera un sentido propio. En ese sentido, no sería una lucha contra la metáfora. Zourabichvili (2011, 47 ss.) se ha preguntado por qué seguir haciendo alusión a las distribuciones de la lengua a la hora de pensar los conceptos. ¿Por qué no más bien fugar los recortes preestablecidos, y seguir los cambios intensivos que adquieren las palabras trazadas, antes que definir sus movimientos según su capacidad de remitir a otras?

\section{REFERENCIAS}

ABRAHAM, N.; Torok, M. L'écorce et le noyau. París: Flammarion, 1987.

DERRIDA, J. Fors: Les mots anglés de Nicolas Abraham et Maria Torok. In Abraham, N.; Torok, M. Cryptonymie. Le verbier de l'homme aux loups. París: Flammarion, 1976, p. 7-73.

NIETZSCHE, F. Ecce Homo. Cómo llega uno a ser lo que es. Obras completas, Volumen IV. Escritos de madurez II y complementos a la edición. Madrid: Tecnos, 2016, p. 773-859. Traducción y notas de Manuel Barrios Casares. 
SALVATERRA, V. C. Comer al otro: retoricas de la alimentación: una lectura del seminario inédito manger l'autre de Jacques Derrida (1989 - 1990). Trans/Form/Ação: Revista de Filosofia da Unesp, v. 43, n.3, 2020.

SALVATERRA, Valeria Campos. Comer al otro: retoricas de la alimentación: Una lectura del seminario inédito Manger l'autre de Jacques Derrida (1989 - 1990). Trans/Form/ Açáo: revista de filosofia da Unesp, vol. 43, n. 4, p. 343 - 368, 2020.

ZOURABICHVILI, F. La littéralité et autres essais sur l'art. París: Presses Universitaires de France, 2011.

Recebido: 22/10/2020

Aceito: $26 / 10 / 2020$ 
ROJAS, C. D. 